\title{
Prova Criminal: o Testemunho Infantil
}

\author{
eNey OFayet de OPouza Stiniox
}

Professor de Direito Penal (PUC/RS), Especialista em Ciências Penais (PUC/RS), Mestrando em Ciências Criminais (PUC/RS), Advogado.

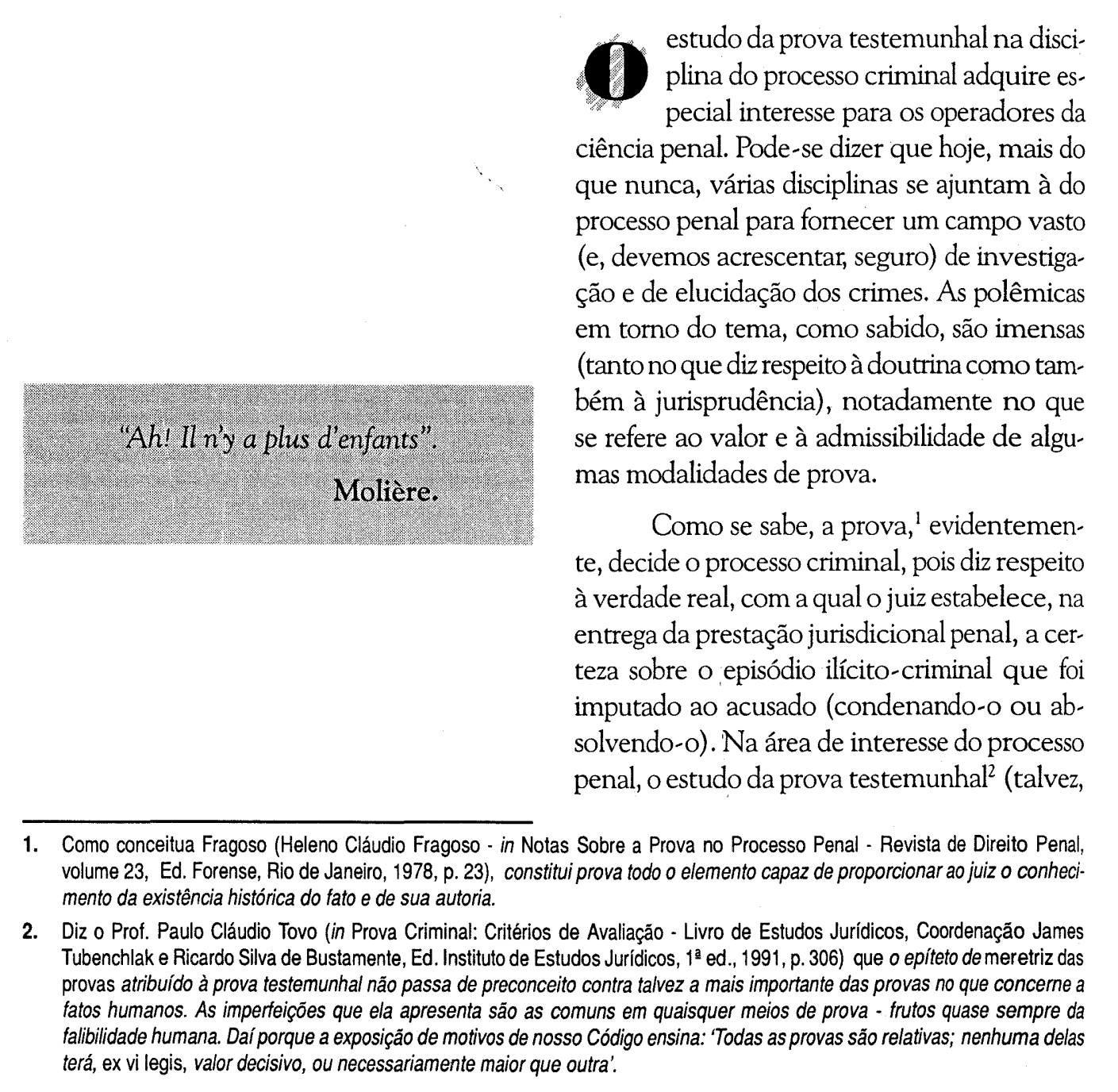

Revista da Faculdade de Direito da UFRGS, v. 16, 1999 
embora essa hierarquia, com efeito, não exista a mais importante de todas as provas) reveste se de uma importância fundamental e decisiva. $^{3}$

E, naquilo que é pertinente à prova testemunhal, adquire importante relevo uma modalidade específica desta prova ${ }^{4}$ carreada em juízo (ou mesmo em uma fase pré-jurídica), que é a prova testemunhal infantil, ${ }^{5}$ haja vista as suas vicissitudes e peculiaridades. Abordar os aspectos fundamentais da prova testemunhal infantil (com todas as suas principais nuanças, quer do aspecto processual, quer do aspecto psicológico) é o escopo deste trabalho. ${ }^{6}$
O testemunho infantil, efetivamente, sempre preocupou a justiça penal, em todas as fases de sua evolução histórica, ${ }^{?}$ constituindo-se em fator (ao lado do sexo, da situação civil, da vida pregressa etc.) que, muitas vezes, incapacitava a pessoa de testemunhar.

Hodiernamente, o nosso ordenamento jurídico não estabelece obstáculos à participação de menores, como testemunhas, no processo criminal. E isto porque, segundo o Código de Processo Penal, qualquer pessoa ${ }^{8}$ pode ser testemunha.

Deste modo, a criança, igualmente, pela percepção sensorial, pode tomar conta-

3. O que levou o grande Jeremias Bentham a dizer que a arte do processo não é senão a arte de administrar as provas (citado por Walter Coelho, in Prova Indiciária em Matéria Criminal, Ed. Fabris, 1996, p. 11)

4. Bem diz Marques (José Frederico Marques - in Elementos de Direito Processual Penal - volume II, Ed Bookseller, Campinas, 1997, p. 309) que prova testemunhal é a que se obtém com o depoimento oral sobre fatos que se contêm no litígio penal. As pessoas que prestam esse depoimento têm o nome de testemunhas, às quais, segundo definição de Von Kries, são terceiros chamados a depor, sobre suas percepçōes sensoriais, perante o juiz.

5. O Código de Processo Penal, em seu artigo 202, permite que toda a pessoa possa ser testemunha, năo se deferindo, entretanto o compromisso de dizer a verdade aos a) doentes e deficientes mentais; b) aos menores de 14 anos; $c$ ) aos parentes do acusado mencionados no artigo 206 do Código de Processo Penal, e que são o ascendente ou descendente, ou afim em linha reta, 0 cônjuge ainda separado, o irmão, e também pai, mãe, ou filho adotivo (CPP, artigo 208).

6. Nunca é demais referir-se que vigora entre nós, no que tange à prova no processo penal, o principio da verdade real, que corresponde à busca da certeza sem obstáculos ou limitaçōes legais na valoração da prova (sistema do livre convencimento adotado em nosso sistema - artigo 157, do Código de Processo Penal e artigo 297, do Código de Processo Penal Militar). Desta sorte, o juiz, ao estabelecer, na sentença, o fim da lide penal, pode apoiar-se na prova que se lhe aprouver, desde que motive, suficientemente, o seu convencimento. Dai porque, tem-se como válido o testemunho infantil para gerar uma nota de censurabilidade jurídico-penal. Tem-se, por fim, de referir, conjuntamente à Exposição de Motivos do Código de Processo Penal que o livre convencimento não quer dizer puro capricho de opinião ou mero arbítrio na apreciação das provas. O juiz está livenal, preconceitos legais na aferição das provas, mas näo pode abstrair-se ou alhear-se ao seu conteúdo.

7. O Código de Manu já preconizava: "Ś quando o fato houver ocorrido em lugar ormo, é que a cranca poC nesse caso o juiz equiparará 0 depoimento dela a do lienado (citado por Adaberto José 0 . Ţa podera ser inquirida; mas nesse caso o juiz equiparará o depoimento dela ao do alienado (citado por Adalberto José Q. T. de Camargo Aranha - in Da Temis Libreria, Colômbia, 1982, p. 105/106) também acrescenta Florian (in De Las Pruebas Penales - tomo II, $3^{\mathrm{a}}$ ed., Editorial En cuanto a los impúberes, dada naturalmente su condición juŕdica los menores tenían también la facultad de rendir testemonio. de numerosos pasajes de lad fuentus.

8. Como remarca o Prof. Tornaghi (Hélio Tornaghi, in Curso de Processo Penal, v. 1, Ed. Saraiva, 1991, p. 397), o emprego da palavra pessoa (no Código de Processo Penal) está a mostrar que somente o homem (e o homem é gênero que abraça as mulheres - v. Dicionário humarístico, de Folco Masucci, p. 81, $n^{9} 692$ ) pode ser testemunha. Um animal pode ser levado a juízo, por exemplo, para reconhecer, pelo faro, um ladräo, para repetir o que ouviu (papagaio), para provar que um cavaleiro poderia ter saltado a cavalo uma determinada distância etc. Mas não serão testemunhas e sim instrumentos capazes de ministrar indícios.

Revista da Faculdade de Direito da UFRGS, v. 16, 1999

to com o delito, dele despontando como testemunha, inexistindo qualquer óbice ou escolho para que no processo assuma e desempenhe essa posição, com o único senão de que não será compromissada. ${ }^{9}$ Admitese, assim, o depoimento infantil como meio de prova, mesmo porque, em certos crimes, é a única existente (porém será defeso, como visto, o compromisso de dizer a verdade ao menor de catorze anos), mas, por outro lado, reconhece-se as dificuldades em se estabelecer, por meio dele, a verdade real. ${ }^{10}$

Deve-se, portanto, perscrutar do valor jurídico que se há de conferir ao depoimento testemunhal (ou mesmo vitimário) infantil, ${ }^{11}$ pois vários fatores - que, a seguir, serão relacionados e debatidos - o inviabilizam.

9. Conforme: Fernando de Almeida Pedroso - Da Prova Penal. Ed. Aidê, Rio, 1994, p. 63

10. Aduz Rogue de Brito Alves (in Ciência Criminal, Ed. Forense, 1995, p. 189) que "pedagogos, psicólogos, psiquiatras, juristas e tratadistas da prova fazem as maiores restriçōes acerca das declaraçōes de crianças, sobre os depoimentos infantis e somente tratadistas da prova fazem as maiores restriçöes acerca das decta

11. Assim, a jurisprudência: Testemunha - Menor - Acusação nela esteada - Admissibilidade. "Não se contesta que o testemunho infantil deve ser recebido com reserva, mas não pode ser afastado in limine, máxime quando encontra ressonância na prova indiciária" (RT 430/344). Testemunha - Menor - Amparo em prova idônea existente nos autos. "As restriçōes que, em tese, são feitas ao testemunho infantil entendem-se cabiveis quando ele é o único elemento de que se dispōe para alicerçar a decisão. Quando, porém, está amparado por prova idônea que o confirma, não se vê razão ou motivo para que dele se descreia". RT 242/ 98. (Citados por Mohamed Amaro - Jurisprudência e Doutrina Criminais, $2^{q}$ v., Ed. RT, São Paulo, 1979, p. 912).

12. Julio Fabbrini Mirabete (in Código de Processo Penal Interpretado, Ed. Atlas, São Paulo, 1994, p. 255) sustenta que o depoimento infantil deve merecer valor probatório quando a criança relata fato de simples percepção visual e de fácil percepção, porque em regra se presume a pureza do menor, o que the concede credibilidade.

13. Convém registrar-se a critica feita por Mittermayer (in Tratado da Prova em Matéria Criminal, Livraria do Editor, Rio, 1871, p. 109): a incapacidade das crianças. Por maior que seja o valor que se dê à sua candura, às suas ingênuas palavras, que, sem calcular as consequências, só exprimem o que realmente caiu sob os seus sentidos, o legislador deverá receiar da leviandade natural do seu espirito, da falta dos seus meios de observação, do seu habito de so verem as coisas superficialmente e de contentarem-se com a primeira impressão; e, finalmente, uma consideração das mais fortes o fară recuar, é a experiência tăo frequente de que a sua jovem imaginação mistura sempre imagens errôneas com as observaçöes reais.

14. Daí existirem julgados realçando que todos os depoimentos têm valor equivalente e a idade, por si só, não constitui elemento para diminuir-hes o grau de certeza.

15. Outra năo é a liçăo do grande Gorphe: "Es increible que en nuestra época de progreso cientifico, la simple palabra de un niño, flatus vocis, inconsistente, pueda decidir de nuestros bienes más sagrados, del honor y de la libertad del hombre" (in La Critica del Testemonio, Editorial Reus, 1933, p. 117)

16. No mesmo sentido: Luiz Régis Prado, (in Falso Testemunho e Falsa Perícia, Ed. Saraiva, 1984, p. 16), para quem o testemunho infantil é perigoso e difficil por fatores morais e psicológicos. A mentalidade da criança, incapaz de compreender os fatos humanos, imaginativa e criadora, vive num mundo ideal antes de chegar à realidade.

Revista da Faculdade de Direito da UFRGS, v. 16, 1999 

seguintes: imaturidade psicológica: a) a rações infantis sejam coerentes e confortantes de outros dados da prova) poderão estribar sentenças penais condenatórias.

Os fatores psicológicos que tornam deficientes os testemunhos infantis são os imaturidade orgânica ${ }^{17}$ do infante traz a imaturidade funcional, com o que o desenvolvimento psíquico será incompleto; ${ }^{18} \mathrm{~b}$ ) a imaginação: ${ }^{19}$ atua duplamente na criança: meio de defesa (mentira defensiva ou interesseira) ou de satisfação de desejos (brinquedos fantasiosos) $;^{20}$ e c) sugestibilidade: ${ }^{21}$ é bem acentuada nas crianças, surgindo mais ou menos aos cinco anos de

17. Trata-se a imaturidade orgânica

idade, atinge seu ponto máximo em torno dos oito anos para, a partir de então, entra em decrescimento.

Há também os fatores morais que tornam os testemunhos infantis deficientes. Pode-se, mesmo, falar em uma espécie de imaturidade moral. A moralidade não é um fato inato, porém adquirido pela criança com base em estímulos ambientais e pres sões externas.

Ao início, na tenra idade, a criança mente, sem a menor intenção, mas porque age com força imaginativa, como defesa, como uma arma etc. Depois, fatores ambientais e pressões sociais exógenas (família, escola, meio pleto, imperfeita será, portanto, a função que se lhe é respectiva. materno, é um ser incompleto, cuja vida psíquica se reduz à expressão mais simples: a sensaçāo, que se traduz em reflexos. logo após, remarca que (na criança) os órgãos dos sentidos se tornam bem depressa suficientemente perfeitos para recolher estímulo exterior, mas a consciência só muito tarde atinge aquela complexa harmonia que torna possivel a exata transformaçấo da sensação em percep̧̧ão.

19. Já Rassier (citado por V. César da Silveira - Tratado da Responsabilidade Criminal, volume III, Ed. Saraiva, 1955, p. 1292/1293) criança na mapler J. P. Porto Ca o (in Psicologia Judicíria

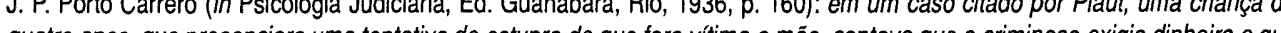
quatro anos, que presciana

20. Em sua obra clássica (La Prueba - Editorial TEMIS Librería - Colombia - 1982, p. 34), O Tschadek relata o seguinte caso: en un ciudad austriaca se tramitó, pocos años há, un juicio contra un odontólogo a quien habla consultado en visperas de Navidad una niña de doce años a la que él conocía desde la primera infancia. Durante el tratamiento, la pequeña le contó que sentía intensos dolores en la región abdominal y que su madre temía que vinieran del apéndice. Entonces, el odontólogo palpó la zona de apéndice com el propósito de informar, dado el caso, a la mamá que también era amiga suya. Como posteriormente habrían de confirmarlo los testigos, la niña salio muy tranquila del consultorio. En la casa conto que el odontólogo le había tocado la región varios pacientes, amén de la declaración modificada de la niña. Para mí no cabe duda que la menor realmente creía haber dicho la verdad y que, tal vez, un deseo reprimido, que la palpación del vientre despertó, hubiera motivado la apreciación totalmente equivocada de la situación

21. Trata-se da capacidade de modificar a realidade da percepção a partir da sugestão que se the é proposta. Pode-se mesmo falar em mentira sugerida (expressão que buscamos em Gorphe), ou seja, a mentira sugerida deriva da sugestão alheia, como a referia que a criança não é dotada de razão, que domina no adulto e determina o valor moral das açōes humanas. Na criança retra idéias; não pode existir na infânci que não adquiriu, aind a nočão do la larga experiencia, de numerosas associaçoes de

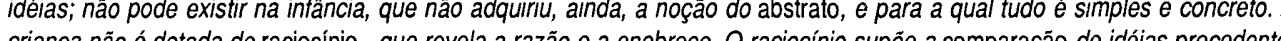
mister adquindas, malindo-se pelo grau de clareza e exaldáo com o qual se apreclam as coisas. Ora, para bem aprecia-las pubiana e intentado violarla. Hasta tal punto abundaba el relato en detalles que el presunto delincuente fue condenado en primeira instancia, y solo más tarde se comprobó su inocencia a la luz de las deposiciones de la ayudante del consultorio y de religioso etc.) indicam que a mentira deve ser relegada, ainda que prejudicando o prazer as vantagens que pode proporcionar; por fim, a censura exterior interioriza-se e o superego

Assim, a imaturidade moral ${ }^{23}$ da criança não admite um valor pleno ao depoimento infantil. ${ }^{24}$

É de remarcar-se, também, que novas técnicas, produzidas e desenvolvidas cuida de evitar a mentira. ${ }^{22}$ na ciência psicológica, têm contribuído para se realçar o valeur du témoignage des se relacionam aos casos em que as crianças são vítimas de delitos (principalmente os sexuais). ${ }^{25}$ Por outro lado, não se pode olvidar das situações em que as crianças são preparadas, ${ }^{26}$ apresentando traumatismos adrede produzidos para materializar o suposto delito, ou então se enfants en justice, sobretudo àquelas que expressão, por si só, já o indica; a sugestão é freqüente, nas falsas acusaçóes devidas a crianças. Essa sugestão nem sempre é intencional: muito freqüentemente é o próprio interrogatório inicial dos pais que indica à criança a invenção. O caso do cura de Etampes é clássico. Uma professora deu queixa contra o sacerdote, acusando-o de atentados ao pudor de algumas de suas alunas. Eis a origem do caso: notara a mestra que aquelas meninas tinham hábitos viciosos; interroga com severidade umá delas: "Diga, foi...quem foi?" E a pequena, atarantada, a responder: Foi...foi...o sr..." - "O sr., quem? - replica a mestra; aqui so há duas pessoas a quem chamamos senhor: 0 sr. Prefeito e o sr. cura." E a menina, crente de que a resposta encerraria o incidente: "Foi o st. cural". O médico legista, interrogando mais habilmente uma das vítimas, pode descobrir o verdadeiro autor; mas todas
elas acusaram o sacerdote. (Citado por Porto Carrero, p. 161/162).

22. Ainda o escólio de Altavilla (ob. cit., p. 79) que, com clareza, abordando os aspectos psicológicos, propriamente ditos, esclarece que ao se estudar as 'mentiras conscientes', tem-se de reconhecer que a razẫo da sua frequência á constituída pelo fato da mentira representar um meio de luta pela existência: "Todos os seres débeis e os agregados sociais inferiores e anormais se servem da mentira como meio de luta. Basta observar a forma como se produz a mentira nas crianças, para nos convencermos de que ela é uma manifestaçẫo do instinto da conservação e, com frequência, uma produção inconsciente, que tem, algumas vezes, as características daqueles movimentos reflexos que esse instinto impöe aos nossos músculos, como quando, num queda, as mãos se estendem para diante a adoçá-la, ou a um gesto de ameaça as pálpabras se cerram para proteger os olhos". É que a criança, no seu mórbido egoismo, na sua 'polimorfa perversidade', como diria Freud, na impulsividade dos seus estímulos, com um fraco discernimento, com uma insuficiente inibição, diz, indiferentemente, o verdadeiro ou o falso, conforme o seu cego utiltarismo a faz considerar, para satisfação de uma necessidade imediata, mais conveniente uma coisa ou a outra. Ela é

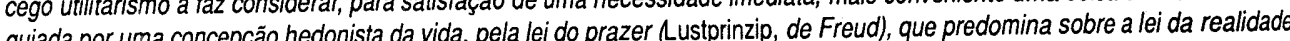
gulada por uma concepço ho num (Reall alprina da iza da a ma

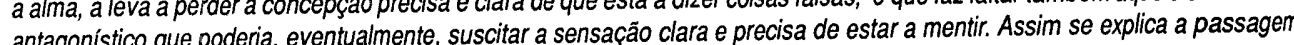
antagonistico que podentia, eventa mentira consciente para a inconsciente.

23. Conforme Cesár Silveira (ob. cit. p. 1.296), citando vários escritores: "tout enfant, en realité, est un petit sauvage. A criança é apudica; a criança, como o animal, não tem pudor, eis que o pudor é característico da puberdade".

24. Adalberto Camargo Aranha - ob. cit. p. 147

25. Recentemente, psicólogos americanos apresentaram um método bastante simples (e, dizem, eficiente) para descobrir se uma determinada crianca foi vitima de algum crime de conotacăo sexual. Trata-se de bonecos, que reproduzem as figuras familiares (por exemplo: se, em um determinado caso, a criança tem pai e mãe, e existe a suspeita de abuso sexual praticado pelo pai, a (por exemplo: se, em um determinado caso, a criança tem pai e máe, e existe a ao final, termina por demonstrar nesta atividade criança brinca com os bonecos (com as representaçöes dele e de seu pai), e, ao final, termina por demonstrar nesta atividade lúdica aquilo que se the ocorreu em realidade), com os quais a crianca

26. É o escólio de Luigi Battistelli (in A Mentira nos Tribunais, Ed. Coimbra Ltda., Coimbra, 1963, p. 113): As crónicas judiciais abundam em falsas acusaçôes, em denúncias baseadas nas palavras mentirosas de um rapazinho ou de uma rapariguinha, em testemunhos falsos, habilmente insinuados no acanhado espirito de uma criança, com um fim utilitário bem determinado, e 0 facto repete-se com muita frequência. 
aproveitam lesões pré-existentes, pois são comuns as vulvites nas meninas. Atribuem-se então essas lesões a práticas libidinosas, que as crianças sugestionadas descreverão. ${ }^{27} \mathrm{~A}$ História, como acentua o Prof. ROQUE DE BRITO ALVES, registra diversos casos de erros judiciários com apoio em depoimento infantis, bastando recordar a indigna acusação do filho de Maria Antonieta, sob sugestão, contra a mesma. ${ }^{28}$

Todos estes aspectos, que foram, perfunctoriamente, abordados, demonstram a fragilidade da prova angariada por meio dos testemunhos infantis. ${ }^{29}$

De tal arte que, quer por fatores psicológicos, quer por fatores morais, deve ser (haja vista o princípio do livre convencimento motivado das provas - que inspira o direito processual penal brasileiro - e que permite o depoimento testemunhal infantil como meio de prova), aceita com (muitas) reservas a prova testemunhal feita por meio dos testemunhos de crianças, pois é certo que esta modalidade específica de prova testemunhal é, muitas vezes, a única de que se dispõe para a perfeita elucidação do delito. Por outro lado, esse testemunho pode ser vantajosamente aproveitado, desde que haja precaução em relação à forma de sua obtenção, concluindo-se que, até o momento, não se houve a Justiça Criminal de forma exitosa no sentido de produzir, com segurança, a prova a partir do depoimento das crianças. Este será, portanto, o desafio lançado às ciências (sobretudo em relação à Psicologia Criminal), para, no futuro, possibilitarem a realização desta modalidade de prova com um juízo de plena e eficaz certeza, colaborando, decisivamente, para a existência de uma Justiça Criminal mais eficiente.

\section{Bibliografia}

ALTAVILlA, Enrico. Psicologia Judiciária, Armênio Amado Editor, Coimbra, 1955.

ALVES, Roque de Brito. Ciência Criminal, Ed. Forense, Rio de Janeiro, 1995.

AMARO, Mohamed. Jurisprudência e Doutrina Criminais, 2º v., Ed. RT, São Paulo, 1979.

ARANHA, Adalberto José Q. T. de Camargo. Da Prova no Processo Penal, Ed. Saraiva, 1996.

BATTISTELLI, Luigi. A Mentira nos Tribunais, Ed. Coimbra Ltda., Coimbra, 1963.

CARRERO, J. P. Porto. Psicologia Judiciária, Ed. Guanabara, Rio, 1936.

COELHO, Walter. Prova Indiciária em Matéria Criminal, Ed. Fabris, 1996.

FLORIAN, Eugenio. De Las Pruebas Penales - tomo II, 3 a ed., Editorial Temis Libreria, Colômbia, 1982.

\section{Conforme Hélio Gomes - Medicina Legal, Liv. Freitas Bastos, 1957, v. 1, $4^{a}$ ed., p. 384}

28. Obra citada, p. 189.

29. Claro que a crítica à prova testemunhal infantil também se espraia para toda a prova testemunhal. Assim Edmond Locard (in A Investigação Criminal - Ed. Saraiva, São Paulo, 1939, p. 89), ao referit que esse modo de prova (a testemunhal) aparece-nos como as falhas save remo graveme, una imo suba que modicam a inagem ao sabor da vildade daquem conta e a compoem de acordo com as sugestoes reciprocas das outras testemunhas; a suspeita da mentira histérica, da mitomania, da sugestão ou da hipnose.
FRAGOSO, Heleno Cláudio. Notas sobre a Prova no Processo Penal - Revista de Direito Penal, volume 23, Ed. Forense, Rio de Janeiro, 1978.

GOMES, Hélio. Medicina Legal, Liv. Freitas Bastos, 1957.

GORPHE, Francois. La Critica del Testimonio. Editorial Reus, Madrid, 1933.

LOCARD, Edmond. A Investigação Criminal, Ed. Saraiva, São Paulo, 1939.

MARQUES, José Frederico. Elementos de Direito Processual Penal - volume II, Ed. Bookseller, Campinas, 1997.

MIRABETE, Julio Fabbrini. Código de Processo Penal Interpretado, Ed. Atlas, São Paulo, 1994.
MITTERMAYER, C. J.. Tratado da Prova em Matéria Criminal, Livraria do Editor, Rio, 1871

PEDROSO, Fernando de Almeida. Da Prova Penal. Ed. Aidê, Rio, 1994.

PRADO, Luiz Régis. Falso Testemunho e Falsa Perí cia, Ed. Saraiva, 1984.

SILVEIRA, V. César da. Tratado da Responsabilidade Criminal, volume III, Ed. Saraiva, 1955.

TORNAGHI, Hélio. Curso de Processo Penal - v. 1., Ed. Saraiva, 1991.

TOVO, Paulo Cláudio. Prova Criminal: Critérios de Avaliação - Livro de Estudos Jurídicos, Ed. Instituto de Estudos Jurídicos, $1^{\text {a }}$ edição, 1991.

TSCHADEK, 0., La Prueba, Editorial Temis Librería Colômbia - 1982 